\title{
Sustainable Design of Bamboo-Based Composite Sheet in Surface Decoration Field
}

\author{
Enchang Zhang ${ }^{\mathrm{a}}$, Xiaoqian Qiu ${ }^{\mathrm{a}}$, Huawei Pu ${ }^{\mathrm{a}}$, Yuxiang $\mathrm{Yu}^{\mathrm{a}, 1}$, Zixuan Deng ${ }^{\mathrm{a}}$ \\ ${ }^{a}$ Lab of Material Innovation and Intelligent Interaction, Zhejiang Sci-Tech University
}

\begin{abstract}
The bamboo-based composite sheet (BCS) based on sustainable theory was designed to improve the utilization of bamboo waste as well as provide a green and renewable product in the surface decoration field. The influence of color, width, proportion for BCS was studied to develop a preparation technology. The perception evaluation (aesthetic value and emotional characteristics) of BCS was analyzed. These results showed when the bamboo proportion was at a low level (10\%), the perception evaluation of BCS was almost unaffected by the color and width of bamboo waste. As the bamboo proportion increased constantly, BSC gave a stronger feeling of lively, traditional and warm. The BCS with thin bamboo waste gave a sense of clean and regularity. On the contrary, the BCS with thick bamboo waste was more suitable for creating a dynamic and radical environment. The BCS with yellow bamboo waste gave a feeling of exquisite, modern, and warm, while green bamboo waste gave a sense of unordered, robust, traditional, and cold.
\end{abstract}

Keywords. Sustainable design, bamboo waste, surface decoration, perception evaluation

\section{Introduction}

With the deterioration of the global environment, the concept of green, low-carbon, and sustainable development has gradually become an international consensus. Thus, sustainable design has become a prominent way for designers to protect the environment [1-3]. Integrating the sustainable concept into design products can gradually change people's lives and behavior, thus promoting a green and sustainable, harmonious environment.

Sustainable design is a kind of strategic design activity to construct sustainable solutions based on the economy, environment, and society in a balanced way. The principles of sustainable design mainly include consumption, ecology, human, and proper design management [4]. The standard methods of sustainable design are using green and eco-friendly materials [5], recycling abandoned products [6] and transforming renewable energy [7].

Bamboo, a well-known green and renewable material, is widely used in the field of construction and furniture. However, the processing utilization rate of bamboo is not high, and the waste generated during the processing is nearly $60 \sim 70 \mathrm{wt} . \%$ [8]. The main methods to deal with bamboo waste are landfills and incineration, resulting in a large amount of resource waste [9]. The high-valued resource utilization of bamboo waste has become a research hotspot under the guidance of sustainable design theory. Feng et al. [10] developed a novel bamboo product with a corrugated structure from bamboo waste. The thickness swelling value of this bamboo-based particleboard without any waterproofing treatment met the requirements of EN standard. Wu et al. [11] prepared a

${ }^{1}$ Correspondence information: Yuxiang Yu, Lab of Material Innovation and Intelligent Interaction, Zhejiang Sci-Tech University, 928 Seconded Avenue, Xiasha High Education Zone, Hangzhou 310018, China, yuyuxiang0612@zstu.edu.cn. 
composite decorative board from wood and bamboo, and its mechanical properties had exceeded the standard of the ordinary wood-based board. However, the sustainable design of bamboo waste mainly focuses on the preparation process and performance characterization, but little research on the aesthetic value and user perception of bamboo waste-based products, especially decorative products.

In this paper, the bamboo-based composite sheet (BCS) mixed bamboo waste with polylactic acid (PLA) fiber was developed based on sustainable theory. The effects of color, width, proportion on the aesthetic value and emotional characteristics of BCS were investigated by semantic difference method from three aspects, including colors, vein, and texture. The results cloud provided a new way for the practical application of bamboo waste.

\section{Theoretical research}

\subsection{Sustainable design}

Sustainable design requires the harmonious development of people and the environment, designing products, services, and systems that can meet the needs of contemporary people and ensure the sustainable development of future generations. The concept of sustainability includes not only environmental and resource sustainability but also social and cultural sustainability.

The principle of sustainable design mainly includes four aspects: 1) Low consumption: on the premise that the product achieves a specific function, it is required that fewer materials and energy are consumed during the manufacturing and use process. It is also required that the product have less environmental pollution during or after use [12]. 2) User experience: the functionality of the product needs to be more user-friendly through ergonomics. At the same time, the physiological conditions of the human body under static and dynamic conditions and the needs and health of users should also be considered in the design process [13]. 3) Ecology: sustainable design requires designers to choose environment-friendly materials to achieve the effect of environmental protection [14]. 4) Design management: to reduce the negative impact on the environment, resources need to be rationally allocated in each stage of the product life cycle [15].

Sustainable design methods mainly include the following: 1) Using green and ecofriendly materials: The selective materials should be non-toxic and can be easily recycled when they are no longer helpful or degraded and digested in natural conditions. 2) Transforming renewable energy: creatively use the clean energy that exists in nature or the energy that is about to be consumed in life into the working energy of the product or reduce the consumption of existing energy in the process of product service. In other words, it is to convert solar energy, wind energy, sound wave energy, kinetic energy, and mechanical energy of water flow into electric energy, light energy, and heat energy. 3) Recycling abandoned products: from the perspective of value transfer in the process of use, we should make full use of the residual value of products after consumption. Product recycling and sustainable behavior are jointly decided by designers and consumers. Designers provide products with recycling characteristics for consumers through sustainable design and guide consumers to use products more rationally and efficiently. 


\subsection{Design principles and methods of $B C S$}

\section{(1) Ecology}

The BCS was made by mixing the bamboo waste and polylactic acid (PLA) fiber. Bamboo is a green and renewable material, and using bamboo waste to produce bamboobased products also decreases the pressure of waste on the society and environment [8]. PLA fiber is from agricultural products, such as corn, wheat, etc., which can be naturally degraded [16]. Bamboo waste and polylactic acid fiber are both environment-friendly materials whose processing technic without producing any pollutants. Besides, as biodegradable materials, bamboo and PLA fiber can both be completely degraded to carbon dioxide and water in nature.

\section{(2) User experience}

Considering the $\mathrm{BCS}$ is close to daily life, the decorative function requires designers to pay more attention to products' aesthetic value and style characteristics and possible emotional effects on users. As a long-term used sheet, it is also required that the material should not be harmful to human health. The BCS does not use any adhesive during processing because the PLA fiber is a low-melting material, which can be used as adhesive at a specified temperature. Besides, both bamboo and polylactic acid fiber are eco-friendly materials. This indicates that the BCS is harmless to humans [16].

\section{(3) Aesthetic attributes}

The aesthetic attribute should be sacrificed as little as possible in sustainable design while paying attention to ecology [17]. The BCS is one kind of decorative material that will apply to human lives; its appearance should conform to the aesthetic taste of most people and also should give users a good or pleasant experience and feelings.

\section{Sustainable design practice of BCS}

\subsection{Materials}

Bamboo waste, including yellow bamboo waste and green bamboo waste, was supplied by Tonglu Yunfeng Bamboo Products Factory. PAC fiber was obtained from Jiangsu Yufang New Material Technology Co., Ltd.

\subsection{Preparation of $B C S S$}

Firstly, the bamboo waste with an expanded length of $150 \pm 10 \mathrm{~mm}$, a width of $0.2 \sim 1.5 \mathrm{~mm}$, and $3.0 \sim 6.0 \mathrm{~mm}$ was selected from the bamboo waste. Afterward, the selected bamboo waste was dried at $108 \pm 2{ }^{\circ} \mathrm{C}$ for 24 hours and then cooled to room temperature to get the dried bamboo waste. Thirdly, the dried bamboo waste and polylactic acid fiber were mixed uniformly in different proportions to obtain the bamboo waste-based mixture. Finally, $20 \mathrm{~g}$ of bamboo waste-based mixture was weighed and placed in a metal mold of $100 \times 200 \times 18 \mathrm{~mm}^{3}$. The mixture was heated for $40 \mathrm{~min}$ in an electric blast drying oven with a temperature of $150 \pm 2{ }^{\circ} \mathrm{C}$ and then cooled to room temperature naturally. The specific colors, width, and proportion of bamboo waste are shown in Table 1. 
Table 1 Factors and naming of BCS

\begin{tabular}{cccc}
\hline \multirow{2}{*}{ BCS } & \multicolumn{3}{c}{ Factors } \\
\cline { 2 - 4 } & Color & Width $(\mathbf{m m})$ & Bamboo proportion (\%) \\
\hline 10\%BCS-Yt & Yellow & $0.2 \sim 1.5$ & 10 \\
30\%BCS-Yt & Yellow & $0.2 \sim 1.5$ & 30 \\
50\%BCS-Yt & Yellow & $0.2 \sim 1.5$ & 50 \\
$70 \%$ BCS-Yt & Yellow & $0.2 \sim 1.5$ & 70 \\
$90 \%$ BCS-Yt & Yellow & $0.2 \sim 1.5$ & 90 \\
10\%BCS-YT & Yellow & $3.0 \sim 6.0$ & 10 \\
30\%BCS-YT & Yellow & $3.0 \sim 6.0$ & 30 \\
$50 \%$ BCS-YT & Yellow & $3.0 \sim 6.0$ & 50 \\
$70 \%$ BCS-YT & Yellow & $3.0 \sim 6.0$ & 70 \\
$90 \%$ BCS-YT & Yellow & $3.0 \sim 6.0$ & 90 \\
10\%BCS-Gt & Green & $0.2 \sim 1.5$ & 10 \\
30\%BCS-Gt & Green & $0.2 \sim 1.5$ & 30 \\
$50 \%$ BCS-Gt & Green & $0.2 \sim 1.5$ & 50 \\
$70 \%$ BCS-Gt & Green & $0.2 \sim 1.5$ & 70 \\
90\%BCS-Gt & Green & $0.2 \sim 1.5$ & 90 \\
\hline
\end{tabular}

\subsection{Perception evaluation of $B C S$}

Considering color, vein, and texture as the three dimensions of evaluation, 12 pairs of perceptual semantic and psychological adjectives were selected to make an evaluation scale (Table 2) by the semantic differential method. 50 subjects observed the color and vein of the BCS, touched the texture of the BCS with their hands, and then made judgments based on feelings, understandings, and subjective feelings of words or concepts. The more miniature score indicated that the BCS image was inclined to the left of the adjective; the more significant score indicated that the BCS image was inclined to the right of the adjective.

Table 2 Semantic difference evaluation scale

\begin{tabular}{|c|c|c|}
\hline Dimensions & Factors & Left $\leftarrow$ Phrases $\rightarrow$ Right \\
\hline \multirow{3}{*}{ Color } & Saturation & Plain_-Gorgeous \\
\hline & Hue & Lively_Calm \\
\hline & Brightness & Clean-Dirty \\
\hline \multirow{5}{*}{ Vein } & Order & Regular-Unordered \\
\hline & Density & Tight__Loose \\
\hline & Affinity & Exquisite-Robust \\
\hline & Form & Convergent-Abrupt \\
\hline & Period feel & Traditional-Modern \\
\hline \multirow{4}{*}{ Texture } & Ecology & Artificial_-Natural \\
\hline & Temperature & Warm-Cold \\
\hline & Hardness & Soft_-Hard \\
\hline & Touch & Smooth_-Rough \\
\hline
\end{tabular}

\section{Results and discussion}

\subsection{Effect of bamboo proportion}

The results of semantic difference and photographs of $10 \sim 90 \% \mathrm{BCS}-\mathrm{Yt}$ and $10 \sim 90 \%$ BCS-YT are depicted in Fig. 1. As seen in Fig.1, the BSC with a higher bamboo proportion gave respondents a feeling of lively, robust, traditional, warm, and rough. The possible reason was that the color of bamboo waste is yellow, whose color saturation was high than that of the white color of FLA fiber [18]. As a natural material, bamboo 
waste still retains its original state [19]. So, the BCS with higher bamboo proportion presented more robust, traditional, and rough feelings.

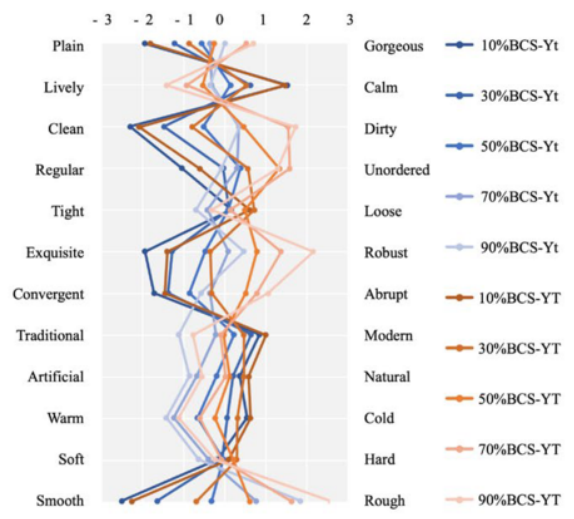

(a)

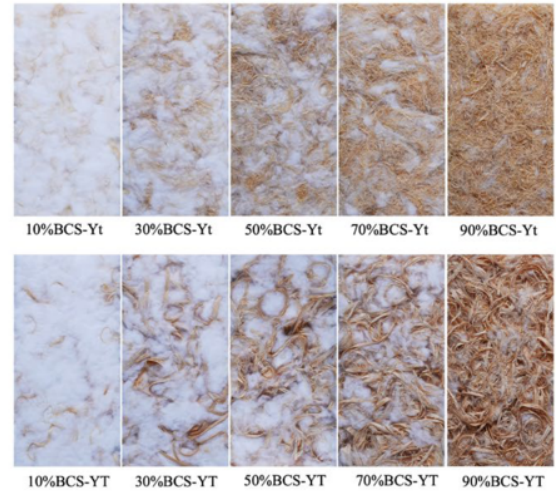

(b)

Figure 1. Semantic difference evaluation results (a) and comparison photographs (b) of BCSs (including width and bamboo proportion factors)

\subsection{Effect of width}

As shown in the Fig.1, compared with $10 \sim 30 \%$ BCS-Yt and BCS-YT, it could be known that when the bamboo proportion was between $10 \%$ and $30 \%$, the BCS with large and small width gave similar impressions. This could be explained that when the bamboo proportion was small, the PLA fiber occupied the main area of BCS, which decreased the influence of bamboo width. Compared with $50 \sim 90 \%$ BCS-Yt and BCS-YT, as the increase of bamboo proportion, the BCS-Yt gave a stronger feeling of clean and regular. This probably because the crimping degree of thin bamboo waste was smaller than that of thick bamboo waste, leading to a more uniform mix between bamboo waste and PLA fiber. The BCS with thick bamboo waste gave respondents a stronger feeling of lively subjective, probably because the crimping degree of thick bamboo waste improved the expression of BCS [20]. Compared with BCS-Yt, the BCS-YT made respondents feel dirty, which was due to the more undulating surface [21,22]. In addition, the BCS-YT gave a feeling of unordered, robust, abrupt to respondents. This was related to the lower mixing uniformity between thick bamboo waste and PLA fiber [18].

\subsection{Effect of color}

The results of semantic difference and photographs of 10 90\%BCS-Yt and 10 90\%BCS-Gt are depicted in Fig.2. As seen in Fig.2, compared with $10 \sim 30 \%$ BCSYt and BCS- Gt, it could be known that when the bamboo proportion was between $10 \%$ and $30 \%$, the BCS produced by yellow and green bamboo waste have roughly the same impressions. This could be explained that when the bamboo proportion was small, the PLA fiber occupied the main area of BCS, which decreased the influence of color. Compared with $50 \sim 90 \%$ BCS-Yt and BCS- Gt, BCS made from yellow bamboo waste gave a stronger feeling of exquisite, modern, and warm impression than BCS made from 
green bamboo waste. The possible reason was that yellow is warmer than green. BCS made from green bamboo waste gave a subjective feeling of traditional, probably because the brightness of green is lower than that of yellow [18]. BCS made from green bamboo waste gave a stronger sense of unorder and robustness. This was related to the color difference between the white of PLA fiber and green was greater than that of yellow, resulting in a clearer texture $[18,23]$.

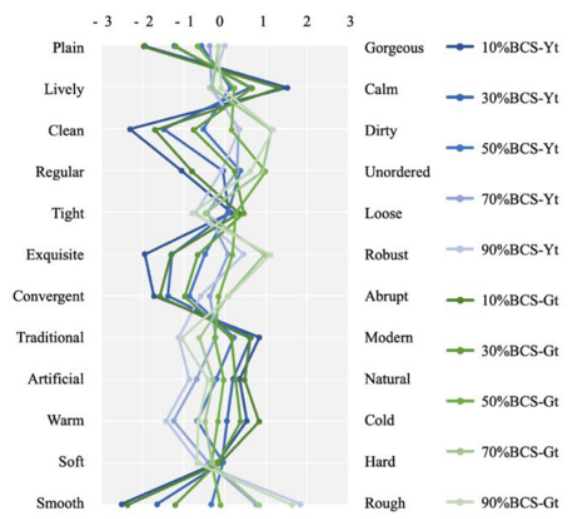

(a)
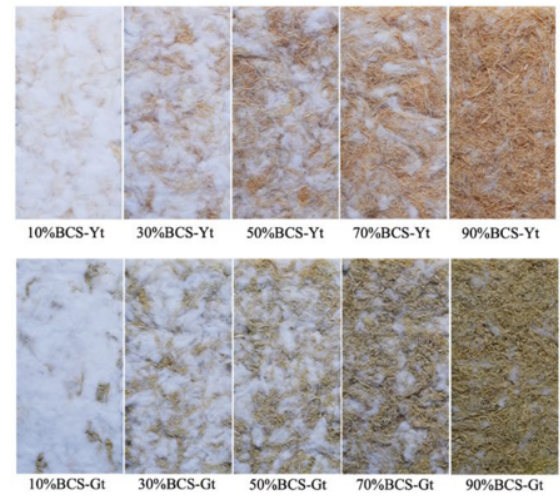

(b)

Figure 2. Semantic difference evaluation results(a) and comparison photographs(b) of BCS with different color bamboo waste

\section{Conclusions}

(1) When the bamboo proportion was at a low level (10\%), the perception evaluation of BCS was almost unaffected by the color and width of bamboo waste.

(2) As the bamboo proportion increased constantly, BSC gave a stronger lively, traditional, and warm feeling. This indicated that BCS with higher bamboo proportion could be applied to products required to express vitality or used to create a warm and traditional environment.

(3) The BCS with thin bamboo waste gave a feeling of clean, regular, which is suitable for products design with a sense of cleanliness and elegance. On the contrary, respondents would choose words like unordered, robust, traditional, and cold to subjectively evaluate their feeling to the BCS with thick bamboo waste. So, BCS with thick bamboo waste was more suitable to create a dynamic and radical environment.

(4) The BCS with yellow bamboo waste gave a feeling of exquisite, modern, and warmth. The BCS with green bamboo waste gave a feeling of unordered, robust, traditional, and cold. So, the BCS with yellow bamboo waste was more suitable to be used in a warm and modern situation, and the BCS with green bamboo waste could easier to create a cool and traditional environment. 


\section{Acknowledgments}

The financial support for this work was from the Humanities and Social Sciences Youth Fund of Ministry of Education (Research on Chinese Traditional Fiber Product Design Strategy Based on DFS Theory, No. 20YJC760037), Philosophy and Social Science Planning Project of Zhejiang Province (No. 21NDQN234YB), and Talent Introduction Program of Zhejiang Sci-Tech University (No. 19082425-Y and 19082153Y) .

\section{References}

1 Kang M., Guerin D.A., The Characteristics of interior designers who practice environmentally sustainable interior design, Environment and Behavior 41(2009), 170-184.

2 Claxton S., A. Kent, The management of sustainable fashion design strategies: An analysis of the designer's role, Journal of Cleaner Production 268(2020), 122112.

3 İ.Gaziulusoy, E. Erdoğan Öztekin, Design for Sustainability Transitions: Origins, Attitudes, and Future Directions, Sustainability 11(2019), 13.

4 D.J. Dongjiu, Y. Wang, 40 Years' Development of Design for Sustainability Theory: From Ecological Innovation to System Innovation, Ecological Economy 37(2021), 221-229.

5 H.P. Liang, Analys on Bamboo Product Design Based on Sustainability, Art \& Design 06(2012), 131-132.

6 P.B. Sanvezzo, M.C. Branciforti, Recycling of industrial waste based on jute fiberpolypropylene: Manufacture of sustainable fiber-reinforced polymer composites and their characterization before and after accelerated aging, Industrial Crops and Products 168(2021), 113568.

7 O. Saadatian, C.H. Lim, K. Sopian, E. Salleh. A state of the art review of solar walls: Concepts and applications, Journal of Building Physics 37(2013), 55-79.

8 L. Zheng, Y.Q. Wu, Y.F. Zuo, Research status and prospects of bamboo residues utilization, World Forestry Research 34(2021), 82-88.

9 X.R. Gu, X.M. Deng, Y.N. Liu, Q.P. Zeng, X.L. Wu, Y.L. Ni, X.J. Liu, T. Wu, P.Y. Fang, B. Wang, Q.Z. Wu, Review on comprehensive utilization of bamboo residues, Transactions of the Chinese Society of Agricultural Engineering 32(2016), 236-242.

10 F. Yang, B.H. Fei, Z.X. Wu, L. Peng, Y.S. Yu, Selected Properties of Corrugated Particleboards Made from Bamboo Waste (Phyllostachys edulis) Laminated with Medium-Density Fiberboard Panels, Bioresources 9(2014), 1085-1096.

11 W.W. Wu, H.C. He, C. Chen, Foaming process of ecological wood-bamboo fiber composite decorative board, Hunan Forestry Science \& Technology 40(2013), 5153.

12 X.B. Wang, J.P. Liu, Y. Fu, The Strategies of Passive Energy-Efficiency Design in Low Energy Building, Applied Mechanics and Materials (2013), 1318-1321.

13 H. B. Yang, Y. T. Feng, Design \& Research of People-Oriented Office Chair, Advanced Materials Research 591-593(2012), 236-240.

14 L. Suárez, J. Castellano, S. Díaz, A. Tcharkhtchi, Z. Ortega, Are Natural-Based Composites Sustainable? Polymers 13(2021), 2326.

15 HONG Zhigang College of Forestry Sichuan Agricultural University Ya'an 
city,China. The application of design management in panel furniture design. Proceedings of 2011 IEEE 12th International Conference on Computer-Aided Industrial Design \& Conceptual Design 1(2011), 4.

16 V. Kumar, N. K. Sharma, R. Kumar, Dielectric, Mechanical, and Thermal Properties of Bamboo-Polylactic Acid Bionano composites, Journal of Reinforced Plastics and Composites 32.1(2013):42-51.

17 J. Zhao, R. Wang, P. Luo, et al. Visual ecology: exploring the relationships between ecological quality and aesthetic preference, Landscape and Ecological Engineering 13(2017), 107-118.

18 T.Y. Jia, X.T. Niu, Evaluation of Color and Visual Characteristics of 22 Kinds of Mahogany Wood, Journal of Northwest Forestry University 32(2017), 250-258.

19 K. Marjan, D. Delia, R. Jessica, The influence of color mixtures on the textural perception of surface design: Deciphering textile methodology in the field of bioplastic design, Color Research \& Application 46.3(2021), 546-556.

20 J. Kim, Y. So, H. Lee, J.H. Kang, Haptic, visual, auditory surface texture perception, IBRO Reports 6(2019), S419.

21 S. Liu, M. Pei, Texture-Aware Emotional Color Transfer Between Images, IEEE Access 6(2018), 31375-31386.

22 L. Zhang, A.C. Rodríguez Urribarrí, H.H. Wang, S. Zhang, Y. Zhang, X.Q. Zeng, Textured Polymer Surfaces Mimicking the Tactile Friction Between Wood and Skin, JOM 73 (2021), 515-523.

23 C. Wang, W. Lu, R. Ohno, Z. Gu, Effect of Wall Texture on Perceptual Spaciousness of Indoor Space, International Journal of Environmental Research and Public Health 17.11(2020). 